\title{
HEALTH ANXIETY, PSYCHOLOGICAL WELL-BEING AND SEXUAL SATISFACTION IN THE CONTEXT OF THE COVID-19 PANDEMIC
}

\author{
Leila BUȚIU ${ }^{1}$
}

\begin{abstract}
The present study aims to identify and evaluate the relationship between health anxiety, psychological well-being and sexual satisfaction. The research was conducted online during the Covid-19 pandemic on a Romanian sample of 155 participants. The results confirmed strong correlations between health anxiety and psychological well-being and also between health anxiety and sexual satisfaction, as well as between psychological well-being and sexual satisfaction. According to previous studies, the present research confirmed psychological well-being to be a significant predictor of the individuals' sexual satisfaction. For the first time in the specialty literature, the results identified health anxiety as a significant negative predictor of sexual satisfaction level and psychological well-being.
\end{abstract}

Key words: health anxiety, psychological well-being, sexual satisfaction, Covid-19 pandemic

\section{Introduction}

This research aims to investigate the relationship between health anxiety, psychological well-being and sexual satisfaction in the context of the Covid-19 pandemic. The paper also aims to identify the explanatory and predictive factors of the variables of interest. There are few studies in the literature that analyze the interaction between health anxiety, psychological well-being and sexual satisfaction, which indicates the need for additional investigations. The main goal is to identify and understand the changes that occur at the individual level and also to provide a scientific basis for prevention actions and design interventions to improve the quality of human life in stressful life contexts, full of uncertainty like pandemic periods.

\subsection{Health Anxiety and Psychological well - being}

Health anxiety is characterized as an excessive preoccupation with having or acquiring a serious illness and, at the same time, having a high level of health anxiety (Salkovskis et al.,

\footnotetext{
1 West University of Timisoara, Timisoara, leila.butiu83@e-uvt.ro , corresponding author
} 
2003). People with health anxiety are engaged, most of the time, in excessive healthrelated behaviors, such as checking the body for signs of illness, avoiding situations or stimuli that are perceived as provoking anxiety.

The cognitive behavioral model illustrates how the assessment and misinterpretation of body symptoms as threatening leads to emotional and physiological feelings of anxiety, safety-seeking behaviors, all of which serve to maintain threat assessments. Therefore, in pandemic contexts, exposure to a large volume of disease-related information can develop and maintain the vicious cycle of health anxiety and can influence other aspects of individuals' personal lives such as psychological well-being, social and occupational functioning (Asmundson et al., 2010). In this regard, since mass - media provides information fast, since it implies short messages, the formulation of firm conclusions and a constant need for new information (Coman, 2007, p.29), different types of mass - media channels can have "different public penetration powers" (Coman et al., 2018, p.41). Health anxiety is a relatively new concept, being derived from hypochondria, which refers to excessive concern or fear of suffering from a serious illness. Health anxiety, although considered milder than hypochondria, is a multifaceted psychological disorder that is characterized by stressful emotions, physiological arousal and associated bodily sensations, thoughts and images of danger and avoidance, and other defensive behaviors. It is often accompanied by ruminating, obsession and compulsive checking of one's own body for signs of illness (Tyrer, 2018). Studies indicate that both increasing and decreasing healthrelated anxiety levels can lead to major problems (GjG, 2004, apud Özdin, S. \& Bayrak Özdin, Ş., 2020). Many individuals suffering from health anxiety are actively involved and eagerly seek health information as well as services to reassure their well-being and calm their anxiety, while others completely avoid seeking and accessing health services (Eastin \& Guinsler, 2006).

Özdin's (2020) study, recently conducted on the urban population of Turkey, is one of the first studies to analyze health-related anxiety in the context of the Covid-19 pandemic. After analyzing the data, the researcher concluded that women, people with psychiatric illnesses in the past or present, as well as people with chronic illnesses have a higher sensitivity and are more aware of their sensations in their own body, so implicitly have an anxiety of increased health.

In another correlational study, conducted on a sample of married women aged 20-60 years, Esmaeili et al. (2020) concluded that health anxiety, perceived stress and selfdisability together predicted up to $50 \%$ of the variance in psychological well-being. Also, perceived stress and health anxiety predicted more than $40 \%$ of the self-disability variant, thus affecting the psychological state of well-being. The data analyzed in the study show that health anxiety is one of the main negative factors that impact the psychological wellbeing of married women in the context of the Covid-19 pandemic.

The present study also includes another psychological variable that is closely related to the well-being of individuals, namely, sexual satisfaction. Relevant results for the present topic show that a higher level of well-being was associated with increased sexual satisfaction (Dundon \& Rellini, 2010, apud Del Mar Sánchez-Fuentes et al., 2014). In contrast, the presence of depression, anxiety and stress, as well as various health conditions have been associated with lower sexual satisfaction (De Ryck et al., 2012, apud Del Mar Sánchez-Fuentes et al., 2014). Even more, another element that can influence the 
well -being and subjective happiness of individuals is the relationships they have with other people, particularly, the quality of those relationships (Coman, 2018, p.245).

Sexual satisfaction is considered to be a relevant aspect of psychological health (Worell \& Goodheart, 2005). According to the original study by Davison et al. (2009), a significant link between self-reported sexual satisfaction and general well-being in women was identified. Thus, addressing sexual satisfaction is an essential component of general wellbeing, especially for women. Therefore, women who self-identify as being sexually dissatisfied have a lower psychological well-being. These findings reinforce the importance of addressing women's sexual health and well-being as an essential component of their health care (Davison et al., 2009; Holmberg et al., 2010). It is essential to understand the connection between the two variables also from the opposite perspective, more precisely how sexual satisfaction changes in relation to wellbeing, both for women and men, in unstable social contexts, with strong psycho-emotional impact like the case of a pandemic. The study by Dundon \& Rellini (2010) shows that psychological well-being, along with other factors, is one of the main predictors of sexual satisfaction in women aged 40-60 years, being considered even higher than sexual function itself. The recent study by Jackson et al. (2019) also shows that a decrease in sexuality in older adults is associated with a much lower psychological state. Older adults who reported a decrease in desire and sexual intercourse experienced a higher number of depressive symptoms and a sharp decrease in the quality of life. The literature contains limited data and information on specific health anxiety in relation to sexual satisfaction, most often mentioning general anxiety, panic disorder or obsessive-compulsive disorder. Alan \& Cevik's (2020) study investigated perceptions of individuals' health and health anxiety during the Covid-19 pandemic in functional health models developed by Marjory Gordon (Karaca, 2016). The results showed that the increased perception of health during the pandemic produced significant differences in the decrease of the model of sexuality and reproduction, which is defined by the dyad satisfaction-dissatisfaction with sexual life and the type of reproduction. This decrease could be interpreted as a kind of avoidance behavior against the risk of contagion (Alan \& Cevik, 2020). The fear of infection and transmission of the disease to the partner that occurs during pandemics in general and occasionally in the case of the Covid-19 pandemic, manifests itself in the form of a decrease in the frequency and quality of sexual intercourse (Baran \& Aykac, 2021). We can conclude then that health anxiety, which is an exacerbation of fear of the disease, can lead to a decrease in sexual satisfaction. The present study aims to provide additional information on the relationship between the two variables and to test, for the first time, whether health anxiety negatively explains and predicts the sex life of individuals, by decreasing sexual satisfaction in the context of the Covid-19 pandemic.

\section{Methodology}

\subsection{Hypotheses}

In relation to previous research in the literature and in addition to it, the present study examined the relationships between health anxiety, psychological well-being and sexual satisfaction in the context of the Covid-19 pandemic. The following hypotheses were formulated: 
Hypothesis 1. There is a negative association between high levels of health anxiety and psychological well-being.

Hypothesis 2. There is a negative association between the high level of health anxiety and the degree of satisfaction of individuals with their sex life.

Hypothesis 3. There is a positive association between the low level of psychological wellbeing and the degree of satisfaction of individuals with their sexual life.

Hypothesis 4. Health anxiety predicts a decrease in sexual satisfaction.

Hypothesis 5. Health anxiety predicts a decrease in the level of psychological well-being.

Hypothesis 6. Psychological well-being predicts sexual satisfaction.

\subsection{Participants and Procedure}

The research was based upon a non-experimental correlational study with a transversal design. The study involved 155 participants, aged between 20-68 years (mean age $=39.18$ years), of whom $54.8 \%(n=85)$ were female, respectively $45.2 \% \quad(n=70)$ male. According to demographic data, $91 \%$ of respondents came from urban areas, $87.8 \%$ had higher education (bachelor's and master's degree), $83.2 \%$ were married or were in steady relationships (between 1-5 years of relationship, respectively over 10 years) and $74.8 \%$ cohabited with their life partner at the time of completing the questionnaire.

Participants were briefed on a topical study to investigate the link between healthrelated anxiety, psychological well-being, and sexual satisfaction in the context of the Covid-19 pandemic. Interested persons were invited to participate online through social networks (Facebook, Whatsapp and Instagram) or via e-mail (directly or via MailChimp), with the written mention that participation in the study is anonymous and voluntary.

\subsection{Instruments}

To measure the level of psychological well-being, we used the Scale for Psychological Wellbeing Scale (PWB - Ryff, C. D., 1989), the version translated into Romanian. The scale includes 42 items, with the following subscales: 1- Autonomy, 2 - Control over the environment, 3 - Personal development, 4 - Positive relationships with other people, 5 - Purpose in life, 6 - Self-acceptance. The answers were organized on a Likert scale, from 1 (total disagreement) to 6 (total agreement). A high score on this scale indicated an increased level of self-reported psychological well-being. The original scale showed very good internal consistency, with Alpha Cronbach for subscales between .86 and .93 (Ryff, 1989). The internal consistency of the PWB scale, compared to our sample, also had a very good internal consistency, with a total Alpha Cronbach of .92

We also used the Short Health Anxiety Inventory (SHAI - Salkovskis et al., 2002), the short version, translated into Romanian, to assess the tendency of individuals to worry excessively about their health. The scale is a self-reporting measure that includes 18 items with multiple answers, 4 answers for each item (A, B, C, D). A high score on this scale indicates a high level of anxiety about health. The original scale in the short version showed a good internal consistency: Alpha Cronbach $=.89$ (Salkovskis et al., 2002). The internal consistency of the SHAl scale, compared to our sample of participants, has a very good 
internal consistency, with a total Alpha Cronbach of .95.

Last but not least, we used the Multidimensional Sexuality Questionnaire (MSQ - Snell et al., 1993), the version translated into Romanian, to assess the psychological trends associated with sexual relations. The questionnaire has 61 items, with 5 items associated to the 12 subscales: 1 - Sexual esteem, 2 - Sexual concern, 3 - Internal sexual control, 4 Sexual conscience, 5 - Sexual motivation, 6 - Sexual anxiety, 7 - Sexual assertiveness, 8 Sexual depression, 9 - External sexual control, 10 - Sexual monitoring, 11 - Fear of sexual intercourse, 12 - Sexual satisfaction. Scores are aggregated for each subscale, and higher values are associated with the relevant trend. The original scale showed a good internal consistency (Alpha Cronbach $=.85$ ). Specifically, the measure of primary interest for the present paper, the original Sexual Satisfaction Scale presented a very good internal consistency, Alpha Cronbach = .90 (Snell et al., 1993). The internal consistency of the MSQ scale, compared to our sample of participants, had a good internal consistency, with a total Alpha Cronbach index of .88. The last scale of the MSQ questionnaire and the most important for the present study was the Sexual Satisfaction Scale, which had a very good internal consistency (Alpha Cronbach $=.91$ ).

\section{Results}

The raw data collected for the present study were interpreted using the IBM SPSS Statistic 20 statistical program. The data distribution was symmetrical and we used parametric statistical methods for data processing.

Table 1

Descriptive statistics, Pearson correlation coefficients and fidelity coefficients for health anxiety, psychological well-being and sexual satisfaction

\begin{tabular}{|c|l|l|l|l|l|}
\hline Observed variables & $\mathbf{M}$ & SD & $\mathbf{1}$ & $\mathbf{2}$ & $\mathbf{3}$ \\
\hline 1. Health anxiety & 17.16 & 11.27 & .95 & & \\
\hline 2. Psychological well-being & 192.52 & 27.73 & $-.65^{* *}$ & .92 & \\
\hline 3. Sexual satisfaction & 11.97 & 5.06 & $-.56^{* *}$ & $.57^{* *}$ & .91 \\
\hline
\end{tabular}

${ }^{*}$ Note. ${ }^{*} p<.05 ; p<.01 ;{ }^{*} p<.001$ (uni-direcional); $N=155$; The $\alpha$ Cronbach coefficients are presented on the main diagonal

Hypothesis 1. There is a negative association between high levels of health anxiety and psychological well-being. The results indicate that we have a negative and significant link between the two variables, $r(153)=-.65, p<.001$. There is a common variance of $42 \%$ between the two variables, with a very strong effect $\left(r^{2}=.42\right)$.

Hypothesis 2. There is a negative association between the high level of health anxiety and the degree of satisfaction of individuals with their sex life. The results indicate that between the two variables we have a statistically negative and significant link, $r(153)=-$ $.56, p<.001$. There is a common variance of $31 \%$ between the two variables, with a very strong effect $\left(r^{2}=.31\right)$.

Hypothesis 3. There is a positive association between the low level of psychological wellbeing and the degree of satisfaction of individuals with their sexual life. The results indicate that between the two variables we have a statistically positive and significant 
link, $r(153)=.57, p<.001$. There is a common variance of $32 \%$ between the two variables, with a very strong effect $\left(r^{2}=.32\right)$.

Table 2

Simple linear regression analysis estimating the predictive validity of health anxiety over sexual Satisfaction

\begin{tabular}{|l|l|}
\hline \multirow{2}{*}{ Predictor } & Sexual satisfaction \\
\cline { 2 - 2 } & Step 1 \\
\cline { 2 - 2 } & $B$ \\
\hline Health anxiety & $-.56^{* *}$ \\
\hline
\end{tabular}

Note: $N=155 ;{ }^{*} p<.05,{ }^{* *} p<.001$

Hypothesis 4. Health anxiety predicts a decrease in sexual satisfaction. We used simple linear regression to check whether health anxiety predicts a decrease in sexual satisfaction. The results of the regression analysis allow us to make accurate predictions ( $F(1,153)=$ $70.15, \mathrm{p}<.001)$ and indicate that health anxiety is a negative and significant predictor of sexual satisfaction $(\beta=-.56, p<.001)$, in the context of the Covid-19 pandemic, explaining $31 \%$ of the variance in sexual satisfaction (adjusted $\mathrm{R}^{2}=.31$ ).

Simple linear regression analysis estimating the predictive validity of health

Table 3 anxiety over psychological well-being

\begin{tabular}{|l|l|}
\hline Predictor(s) & Psychological well-being \\
\hline & Step 1 \\
\hline & $B$ \\
\hline Health anxiety & $-.65^{* *}$ \\
\hline$R^{2}$ & .42 \\
\hline$F^{* *}$ & $110.08^{* *}$ \\
\hline
\end{tabular}

Note: $N=155 ;{ }^{*} p<.05,{ }^{* *} p<.001$

Hypothesis 5. Health anxiety predicts a decrease in psychological well-being in the context of the Covid-19 pandemic. We used simple linear regression to check whether health anxiety predicts a decrease in well-being. Based on the regression equation we can make more accurate predictions than on the average. The results of the regression analysis ( $F$ $(1,153)=110.08, p<.001)$ indicate that health anxiety is a negative and significant predictor of psychological well-being $(\beta=-.65, p<.001)$, explaining $42 \%$ of the variance in the psychological state of well-being (adjusted $\quad R^{2}=.42$ ). 
Table 4

Simple linear regression analysis estimating the predictive validity of psychological wellbeing on sexual satisfaction

\begin{tabular}{|l|l|}
\hline \multirow{2}{*}{ Predictor(s) } & Sexual satisfaction \\
\cline { 2 - 2 } & Step 1 \\
\cline { 2 - 2 } & $B$ \\
\hline Psychological well-being & $.57^{* *}$ \\
\hline$R^{2}$ & .32 \\
\hline$F^{* *}$ & $72.44^{* *}$ \\
\hline
\end{tabular}

Hypothesis 6. Psychological well-being predicts sexual satisfaction in the context of the Covid-19 pandemic. We used simple linear regression to check whether psychological well-being predicts sexual satisfaction. Based on the regression equation we can make more accurate predictions than on the average. The results of the regression analysis ( $F$ $(1,153)=72.44, p<.001)$ indicate that health anxiety is a positive and significant predictor of sexual satisfaction $(\beta=.57, p<.001)$, explaining $32 \%$ of the variance in sexual satisfaction (adjusted $\mathrm{R}^{2}=.32$ ).

\section{Discussion}

We found that an increase in health anxiety has a strong negative effect on well-being. This is in agreement with previous studies (Wilhelmsen, 2017; Esmaeili et al., 2020). People with high levels of health anxiety experienced a decrease in sexual satisfaction in the context of the Covid-19 pandemic. The data are in agreement with the results obtained by Alan \& Cevik (2020) in their research during the pandemic. The authors concluded that increased perceptions of health led to changes in sexual behavior, translated into decreased frequency of sexual intercourse and increased dissatisfaction with sexual satisfaction, which could be interpreted as avoidance behavior against the risk of contagion (Alan \& Cevik, 2020). People with a low level of psychological well-being experienced a decrease in sexual satisfaction in the context of the Covid-19 pandemic. These results are consistent with previous studies (Del Mar Sánchez-Fuentes et al., 2014; Davison et al., 2019) whose results show that a higher level of well-being associated with increased sexual satisfaction and psychological well-being, along with other factors, is considered one of the main predictors of sexual satisfaction, with specific reference to women over the age of 40 . (Dundon \& Rellini, 2010).

Health anxiety explains part of the level of sexual satisfaction felt in the context of the Covid-19 pandemic. Given the fact that there is no such research in the literature, the analyzed data bring an important explanatory and predictive contribution to the relationship between health anxiety and sexual satisfaction. We can conclude that health anxiety is a significant negative predictor of the level of sexual satisfaction felt.

Health anxiety explains part of the level of psychological well-being. Therefore, the higher the level of anxiety about health, the lower the level of psychological well-being in the context of the Covid-19 pandemic. These conclusions are in agreement with the results of previous studies that indicated that health anxiety, perceived stress and self-disability 
together predicted up to $50 \%$ of the variance of psychological well-being (Esmaeili et al., 2020). In our case, only health anxiety alone explains $42 \%$ of the variance in psychological well-being, consistent with recent findings. People being constrained to work from home, to have fewer social contacts can develop anxiety. All the information from the mass-media can raise the level of health anxiety in particular. In this context visits to parks, taking walks can improve their level of anxiety (Swami, V., Khatib, NAM, Vidal-Mollon, J., Vintila, M., Barron, D., Goian, C., Mayoral, O., Toh, EKL, Tudorel, O. \& Vazirani, S. (2020).Certain categories are especially vulnerable, the elderly Eglite, A., Vintila, M., Grinfelde, A., Kanitike, I., 2009, Vintila, M., Marklinder, I., Nydahl, M., Istrat, D., Kuglis, a., 2009), as they often live alone, and have fewer social contacts even in normal times. Also, people with psychiatric disorders, depression, anxiety, panic attacks are especially vulnerable in these times (Barron, D., Vintila, M., Swami, V., 2020, Swami, V., Barron, D., Vintila, M., Ong, HS, Tudorel, O., Goian, C, Wong, KY, Toh, EKL., 2021, Swami, V., Vintila, M., Goian, C., Tudorel, O., Bucur, $V ., 2020)$. Health anxiety is also in relationship with vaccination intention. Perception of the severity of the disease leads to a higher willingness to get vaccinated (Stefanut, A., Vintila, M., Tomita, M., Treglia, E., Lungu, A., Tomassoni, R., 2021).

The psychological state of well-being explains part of the level of sexual satisfaction of individuals. Thus, the higher the psychological well-being, the higher the level of sexual satisfaction. In a pandemic context, the lower the psychological well-being, the lower the level of sexual satisfaction. Previous studies (Dundon \& Rellini, 2010; Jackson et al., 2019) confirm the importance of psychological well-being in relation to sexual satisfaction, a fact confirmed by the data of our study.

\section{Limits of the Study and Future Research Directions}

The starting point of the present study was the small number of researches in the literature that refer to the relationship between health anxiety, psychological well-being and sexual satisfaction, which is also a limitation. Given the strong association between variables and taking into account the predictive component, it would be useful to deepen the topic by initiating future experimental studies that can identify causal links between variables. The present study highlighted a strong association between the three variables, but it didn 't measure the direct influence of the pandemic context on the data obtained. A possible explanation for the values recorded for each variable as well as for the size of the effect, could be influenced by the pandemic context. However, having a cross-sectional design, the study did not include a pre-Covid comparison group, which limits the possibility of making inferences about the causal effect of the pandemic. To clarify this, it would be helpful for future studies to focus on measuring the relationship between these variables in other less stressful life contexts.

\section{Conclusions and Practical Implications}

The present study makes an important contribution to the literature by identifying a strong link between the targeted variables: health anxiety, psychological well-being and sexual satisfaction during the Covid-19 pandemic, as well as identifying health anxiety as an important negative predictor of the level of sexual satisfaction felt and psychological wellbeing. The research also confirmed the predictive role of well-reported psychological well- 
being in terms of sexual satisfaction. As practical implications, the study focuses on the area of health psychology and well-being. Based on the results obtained, psychologists can work closely with specialists to identify the personal resources of individuals, develop strategies and programs of prevention and psychological intervention, applicable in stressful life contexts, to maintain the physical and psychological health people's emotional state. The main goal is to identify vulnerable groups and learn adaptive coping strategies (for example, guided relaxation and mindfulness programs) to maintain a higher quality of life, even in less friendly life environments like the pandemic global crisis.

\section{References}

Alan, S., \& Cevik, A. (2020). An investigation of individuals' health anxiety during the COVID19 pandemic within the framework of the functional health patterns. Perspectives in psychiatric care, $10.1111 /$ ppc.12663

Asmundson, G. J., Abramowitz, J. S., Richter, A. A., \& Whedon, M. (2010). Health anxiety: current perspectives and future directions. Current psychiatry reports, 12(4), 306-312.

Baran, O., \& Aykac, A. (2021). The effect of fear of covid-19 transmission on male sexual behaviour: A cross-sectional survey study. International Journal of Clinical Practice, 75(4), 1-7.

Barron, D., Vintila, M., Swami, V., (2020). An assessment of the dimensionality of a Roanian translation of the schizotypal personality questionnaire and associations with quality of life, self-esteem and life satisfaction. Schizofrenia Bulletin, 46, 226.

Coman, C. (2007). Tehnici de negociere. București: CH Beck.

Coman, C., Rezeanu, C. I., \& Mihalte, S. I. (2018). Highlighting The Image Of The Local Government Institutions In Mass Media Based On The Results Of The Content Analysis. Curentul Juridic, The Juridical Current, Le Courant Juridique, 72, 39-56.

Coman, C. (2018). Happiness as a resilience resource for the social reproduction of human capital in the private sphere. Economic and Social Development: Book of Proceedings, 241-247.

Davison, S. L., Bell, R. J., LaChina, M., Holden, S. L., \& Davis, S. R. (2009). Psychology: The relationship between self-reported sexual satisfaction and general well-being in women. The journal of sexual medicine, 6(10), 2690-2697.

Dundon, C. M., \& Rellini, A. H. (2010). More than sexual function: Predictors of sexual satisfaction in a sample of women age 40-70. The journal of sexual medicine, 7(2), 896-904.

Del Mar Sánchez-Fuentes, M., Santos-Iglesias, P. și Sierra, JC (2014). O revizuire sistematică a satisfacției sexuale. Revista internațională de psihologie clinică și a sănătății, 14 (1), 67-75.

Eastin, M. S., \& Guinsler, N. M. (2006). Worried and wired: effects of health anxiety on information- seeking and health care utilization behaviors. CyberPsychology \& Behavior, 9(4), 494-498.

Eglite, A., Vintila, M., Grinfelde, A., Kanitike, I., (2009). Healthy lifetyle in the elderly's view in Romania and Latvia, Economic Science for Rural Development.

Esmaeili, S., Ghanbari Panah, A., \& Koochak Entezar, R. (2020). Prediction of psychological well-being based on health anxiety and perceived stress with the mediating role of selfhandicapping in married women working in the school of Nursing and Midwifery, Tehran University of Medical Sciences in 2018. Iranian Journal of Nursing Research, 14(6), 0-0.

Holmberg, D., Blair, K. L., \& Phillips, M. (2010). Women's sexual satisfaction as a predictor of well- being in same-sex versus mixed-sex relationships. Journal of Sex Research, 47(1), 1- 
11.

Jackson, S. E., Firth, J., Veronese, N., Stubbs, B., Koyanagi, A., Yang, L., \& Smith, L. (2019). Decline in sexuality and wellbeing in older adults: A population-based study. Journal of affective disorders, 245, 912-917. 10.1016/j.jad.2018.11.091

Karaca, T. (2016). Functional Health Patterns Model-A Case Study. Case Studies Journal Vol. $5,14-22$.

Özdin, S., \& Bayrak Özdin, Ş. (2020). Levels and predictors of anxiety, depression and health anxiety during COVID-19 pandemic in Turkish society: The importance of gender. International Journal of Social Psychiatry, 66(5), 504-511.

Salkovskis, P. M., Rimes, K. A., Warwick, H. M. C., \& Clark, D. M. (2002). The Health Anxiety Inventory: development and validation of scales for the measurement of health anxiety and hypochondriasis. Psychological medicine, 32(5), 843-853.

Salkovskis, P. M., Warwick, H. M., \& Deale, A. C. (2003). Cognitive-Behavioral Treatment for Severe and Persistent Health Anxiety (Hypochondriasis). Brief Treatment \& Crisis Intervention, 3(3), 353-367.

Snell, W. E., Fisher, T. D., \& Walters, A. S. (1993). The Multidimensional Sexuality Questionnaire: An objective self-report measure of psychological tendencies associated with human sexuality. Annals of Sex Research, 6(1), 27-55.

Swami, V., Khatib, NAM, Vidal-Mollon, J., Vintila, M., Barron, D., Goian, C., Mayoral, O., Toh, EKL, Tudorel, O. \& Vazirani, S. (2020). Visits to Natural Environments Improve State Body Appreciation: Evidence from Malysia, Romania and Spain, Ecopsychology, vol.12, no1.1.

Swami, V., Barron, D., Vintila, M., Ong, HS, Tudorel, O., Goian, C, Wong, KY, Toh, EKL. (2021), An examination of the higher-order dimensionality and psychometric properties of a Romanian translation of the schizotypal personality questionnaire (SPQ), Current Psychology, 6/4, 1-12.

Swami, V., Vintila, M., Goian, C., Tudorel, O., Bucur, V., (2020), Mental health literacy of maternal and paternal postnatal depression in a community of Romanian adults, Perspectives in Psychology, 9(3), 147-158.

Ștefanut, A., Vintila, M., Tomita, M., Treglia, E., Lungu, A., Tomassoni, R., (2021), The Influence of Health Beliefs, of resources, of vaccination Histiry and of Health anxiety on intention to accept COVID-19 vaccination, 12.

Tyrer, P. (2018). Recent advances in the understanding and treatment of health anxiety. Current psychiatry reports, 20(7), 1-8.

Vintila, M., Marklinder, I., Nydahl, M., Istrat, D., Kuglis, a., (2009), Health awareness and behaviour of the elderly: between needs and relaity. A comparative study, Revista de Psihologie Aplicata, 11(2), 81-87.

Wilhelmsen, I. (2017). Hypochondriasis or health anxiety. Reference Module in Neuroscience and Biobehavioral Psychology. Elsevier. https://doi.org/10.1016/B978-0-12809324-5.06457-9.

Worell, J., \& Goodheart, C. D. (Eds.). (2005). Handbook of girls' and women's psychological health. Oxford University Press. 